\title{
Ab Interno Goniotomy Combined with $A b$ Externo Trabeculotomy in Advanced Primary Congenital Glaucoma Patients: 2-Year Follow-Up
}

This article was published in the following Dove Press journal: Clinical Ophthalmology

\section{Hazem Helmy (10}

Glaucoma Unit, Glaucoma and Optic Nerve Disease Department, Research Institute of Ophthalmology; RIO, Giza, Egypt
Correspondence: Hazem Helmy

48, Palm City Katameya, Egypt

Tel +20201288882616

Email hazem.helmy@yahoo.com
Introduction: Primary congenital glaucoma (PCG) is a challenging disease that needs to be surgically managed with more innovative methods. Conventional incisional surgery, such as goniotomy and trabeculotomy, has a primary high success rate, but does not seem to be a very effective treatment in advanced stages.

Design: A prospective clinical case study.

Purpose: To qualify the outcome, in terms of success rate, of goniotomy combined with trabeculotomy as a surgical option to treat eyes affected by PCG with a corneal diameter larger than $14 \mathrm{~mm}$.

Patients and Methods: This study included 50 eyes of 50 patients diagnosed with PCG with corneal diameter larger than $14 \mathrm{~mm}$ who underwent ab interno goniotomy combined with ab externo trabeculotomy. Intraocular pressure (IOP) was measured preoperatively and 24 months postoperatively. A statistical analysis was performed to detect correlations between the success rate and corneal diameter, preoperative IOP, age of onset, axial length, and consanguinity. The main outcome was reduction in IOP; secondary outcomes were factors affecting the success rate, complications, and the need for additional surgical intervention to control IOP.

Results: The mean age of the patients was $18.86 \pm 9.94$ months. Males made up $52 \%$ of cases and females $48 \%$ of cases. Positive consanguinity was present in $38 \%$ of cases. Axial length ranged between 20 and $22 \mathrm{~mm}$, with a mean of $20.98 \pm 0.8 \mathrm{~mm}$. Mean preoperative IOP was $29.56 \pm 3.36 \mathrm{mmHg}$, which decreased postoperatively to $12.6 \pm 2.5$, $14.1 \pm 3.2,16.8 \pm 5.5,14.4 \pm 2.3,14.3 \pm 1.6,14.3 \pm 1.6,14.3 \pm 1.6,14.3 \pm 1.7$, and $14.3 \pm 1.7$ $\mathrm{mmHg}$ at $1,3,6,9,12,15,18,21$, and 24 months respectively $(p<0.001)$. Use of medical treatment was decreased from $2.7 \pm 0.4$ preoperatively to $1.4 \pm 0.7$ postoperatively $(p<0.001)$. Hyphema was the only complication that appeared, occurring in $47 \%$ of cases. The success rate was $94 \%$. Complete success (IOP $<21 \mathrm{mmHg}$ without treatment) was achieved in $70 \%$ of cases, $24 \%$ were considered a qualified success (IOP $<21 \mathrm{mmHg}$ with treatment), while failure was documented in $6 \%$ of cases (IOP $>21 \mathrm{mmHg}$ with treatment). The success rate was significantly related to preoperative IOP, corneal diameter, axial length, consanguinity, and age of onset $(p<0.001)$. All cases were followed for 24 months.

Conclusion: $\mathrm{Ab}$ interno goniotomy combined with ab externo trabeculotomy improves the success rate of buphthalmos surgery. A significant correlation was detected between success rate and preoperative IOP, corneal diameter, axial length, consanguinity, and age of onset.

Keywords: primary congenital glaucoma, intraocular pressure, corneal diameter, trabeculotomy, goniotomy 


\section{Introduction}

Autosomal recessive type is a genetic typing of primary congenital glaucoma (PCG). ${ }^{1} \mathrm{~A}$ dominant MYOC mutation is the most common cause of this disease. ${ }^{1,2}$ It occurs at a ratio of approximately 1:1250 in Slovakian countries; 1:30,000 in Western countries, and 1:2500 in Saudi Arabia. ${ }^{3}$ One of its common causes is found to be consanguinity among patients. ${ }^{3-5}$ PCG is a net result of a trabecular meshwork and anterior chamber angle maldevelopment, resulting in high intraocular pressure (IOP) ${ }^{7}$ which is essentially treated surgically, not medically. ${ }^{6}$ In general, PCG patients present with an elongated and enlarged globe with a cloudy cornea due to corneal edema secondary to ruptured Descemet's membrane as well as high IOP. ${ }^{8}$ Medical treatment in such cases may be temporarily used to decrease the IOP and clarify the cornea in order to facilitate surgical intervention., ${ }^{9,10}$ Goniotomy and trabeculotomy are anterior chamber angle surgeries that have a high degree of success as initial surgery. ${ }^{11}$ Goniotomy is considered to be a good option in isolated trabeculodysgenesis in pediatric patients aged less than 2 years. ${ }^{12,13}$ A clear cornea that permits good visualization of the angle structures is an essential parameter for goniotomy. ${ }^{14,15}$ A cloudy and opacified cornea due to markedly elevated IOP is typically found in buphthalmos cases. Trabeculotomy is believed to be the ideal surgery in this situation, ${ }^{15-17}$ while goniotomy can be performed with some effort; typically, the surgeon has to choose between goniotomy and trabeculotomy. ${ }^{18}$ The selection of surgery may depend on the corneal diameter, as successful incisional angle surgery may be restricted to corneal diameters less than $14 \mathrm{~mm} .{ }^{16}$ Many authors recommend trabeculotomy, trabeculectomy, or trabeculectomy with MMC for advanced cases with a corneal diameter greater than $14 \mathrm{~mm} .{ }^{16,19}$ An incisional angle surgerical technique known as goniotomy and trabeculotomy surgery is most commonly used for the treatment of PCG. This depends on making an incision through the anomalous trabecular meshwork and internal wall of Shlemm's canal, aiming for augmentation of the aqueous outflow to reduce the IOP. ${ }^{14,20,21}$ Some authors found that a larger corneal diameter, greater than $14 \mathrm{~mm}$, appeared to be a predicting and prognostic factor for goniotomy and trabeculotomy. ${ }^{16,22-24}$ Furthermore, a modification of incisional angle surgery is highly recommended to improve the results in such cases. ${ }^{16,22,23}$ In developing countries, most PCG patients who ask for medical assistance present at an advanced stage that needs aggressive intervention to save their eyes. ${ }^{6}$ A primary single surgical technique may be a great choice to save these eyes as there would be no time to waste.

In this study, trabeculotomy was used in the upper 120 degrees, combined with goniotomy in the lower 120 degrees of angle in buphthalmic eyes with corneal diameter larger than $14 \mathrm{~mm}$, in order to evaluate the intermediate effect of using both maneuvers during the same session.

\section{Patients and Methods}

This study was conducted in the Research Institute of Ophthalmology (RIO), Giza, Egypt, during 2017-2020. All surgical procedures were carried out by the same surgeon $(\mathrm{HH})$. This study was performed under the tenets of the Declaration of Helsinki of 1975 (1983 revision). The Research Local Ethical Committee approved the protocol of this study. The parent or legal caregivers of all the included cases signed an informed consent form prior to enrollment.

This study is a prospective, randomized study that included 50 eyes of 50 cases diagnosed as PCG. Eligible cases of PCG were diagnosed according to the presence of elevated IOP, enlarged corneal diameter, glaucomatous optic disc cupping, and elongated eye with increased axial lens. All cases were diagnosed by examination under general anesthesia. The preoperative clinical data included the patient's age at time of surgery, in addition to gender, consanguinity, and medical treatment details.

Preoperative examination included complete examination of the anterior segment: a surgical caliper was used to measure the horizontal corneal diameter (white to white); IOP was measured by hand-held Perkins applanation tonometry (Haag-Streit, Harlow, UK), just after the induction of general anesthesia when the patient was just sedated; , and the IOP was determined by calculating the mean of three measurements; gonioscopic examination of the anterior chamber angle was conducted with a Swan-Jacob gonioprism; corneal clarity was measured with the aid of a surgical microscope under high magnification and classification into grade 1 when the iris texture was seen clearly, grade 2 when the iris texture was seen hazily, and grade 3 when the texture was not clearly seen; the fundus was examined by binocular indirect ophthalmoscopy; axial length was measured by A scan ultrasonography; B scan ultrasonography was used to exclude any intraocular 
abnormalities; and high-frequency ultrasound biomicroscopy (UBM) (Sonomed Vumax UBM 35 MHz transducer) to document the angle state and anterior segment. The UBM study included detection of any abnormal membranes, level of iris insertion, and the position and configuration of ciliary processes. Furthermore, an assessment of depth of the anterior and posterior chambers in addition to corneal and lens thicknesses was conducted using UBM.

\section{Inclusion Criteria}

The study included PCG patients. The inclusion criteria were patients with a corneal diameter larger than $14 \mathrm{~mm}$, corneal clarity grade 1 and 2, and no previous history of ocular surgery.

\section{Exclusion Criteria}

Patients with other ocular pathologies and/or congenital anomalies, including iris, cornea, lens, or retina, previous ocular surgery, or severe corneal opacity that may interfere with suitable visualization of the anterior chamber angle were excluded from the study.

\section{Surgical Procedure}

All surgical maneuvers were performed under general anesthesia and complete aseptic conditions by the same experienced glaucoma surgeon $(\mathrm{HH})$.

\section{Goniotomy}

Goniotomy was performed first; the lower angle was the target. Adequate visualization of the lower angle once the gonioprism had been placed on the eye was achieved by turning the patient's head 45 degrees from the vertical and firmly securing it in place. A corneal stab incision was performed just anterior to the corneoscleral limbus. Deepening of the anterior chamber was achieved by the injection of a viscoelastic substance such as Healon. An 18-gauge needle connected to an irrigating fluid as a goniotomy knife was introduced into the anterior chamber and an autoclavable Swan-Jacob gonioprism was applied to permit visibility of the angle details. The goniotomy knife was introduced towards the angle to engage the trabecular meshwork at its midpoint. Successful goniotomy was proved by posterior falling of the iris and the appearance of a white line behind the blade. The corneal wound was securely closed with 10/0 suture and the anterior chamber was completely reformed with balanced salt solution.

\section{Trabeculotomy}

A $6 / 0$ silk was placed under the superior rectus to make a bridle suture. A conjunctiva flap was created with a fornix base pattern and cauterization was used to secure hemostasis. Dissection of a $4 \times 4$ partial thickness scleral flap was achieved and extended up to $1 \mathrm{~mm}$ of clear cornea. Schlemm's canal was approached by making a radial incision about $2 \mathrm{~mm}$ from the limbus or at the junction between the white and bluish transitional zone of the sclera until the canal was entered. A gush of aqueous humor and/or blood is a sure sign of successful entry into Schlemm's canal. A Harms trabeculotome was then introduced to achieve ab externo trabeculotomy, first to the right and then to the left to engage about 120 degrees of circumference of Schlemm's canal. A 10/0 nylon suture was used to secure the partial thickness scleral flap, one on each corner. The conjunctival flap was finally closed using $8 / 0$ polyglactin continuous sutures. Subconjunctival injection of $1 \mathrm{mg}$ dexamethasone and $20 \mathrm{mg}$ gentamycin was performed.

Postoperatively, all patients received steroid treatment (prednisolone acetate 1\%), which was tapered off gradually over a period of 4 weeks, and antibiotics (tobramycin $0.3 \%$ ), which were stopped at 2 weeks after surgery.

\section{Follow-Up}

Postoperatively, all patients were examined at 1 day, 1 week, 1 month, and 3 months, and then 3-monthly thereafter. The follow-up period was set at 24 months.

The main outcome measure was defined as the reduction of IOP. Secondary outcomes were defined as complications, factors affecting the success rate, and the need for further surgical interventions.

Complete success was achieved if the IOP was $>6$ and $<21 \mathrm{mmHg}$ without the need for additional medical therapy; qualified success was achieved if the IOP was $>6$ and $<21 \mathrm{mmHg}$ with medical treatment; and failure was defined as persistent IOP $>21 \mathrm{mmHg}$ with two or more antiglaucoma medications or if another surgical glaucoma intervention was required.

\section{Statistical Analysis}

For all determinations, statistical analysis was carried out using IBM SPSS software release 20 for Microsoft Windows (IBM Corp, Armonk, NY, USA). Means and standard deviations were used to describe quantitative variables, while absolute frequencies were used to describe 
categorical variables. The chi-squared test was used to compare the proportions of categorical data when appropriate. Verification of assumption in parametric tests was achieved with the use of Kolmogorov-Smirnov (distribution type) and Levene (homogeneity of variances). The paired sample test (for normally distributed data) was used to compare means of the same group at two points. A repeated measures ANOVA test (for normally distributed data) was used to compare change over time. Changes in discrete data (number of medications) preoperatively and postoperatively were evaluated by the Wilcoxon signed rank test. Pearson correlation coefficients were used to measure the strength and direction of relationships between two continuous variables. Statistical significance was set at the $5 \%$ level $(p<0.05)$. If $p \leq 0.001$, a highly significant difference was present.

\section{Results}

Data from 50 patients (50 eyes) were acquired and studied preoperatively and postoperatively. The age of the patients ranged from 6 to 40 months, with a mean \pm SD age of 18.86 \pm 9.94 months. Males made up $52 \%$ of patients while $48 \%$ were female. Positive consanguinity appeared in $38 \%$ of patients. All patients included in this study were Egyptians. The mean horizontal corneal diameter was $14.56 \pm 0.8 \mathrm{~mm}$, which ranged between 14 and $16 \mathrm{~mm}$. Axial length ranged between 20 and $22 \mathrm{~mm}$ with mean of $20.98 \pm 0.8 \mathrm{~mm}$. The $\mathrm{CD}$ ratio ranged from 0 to 1 , with a mean of $0.8 \pm 0.4$ (Table 1).

Preoperative IOP among the studied patients ranged from 21 to $36 \mathrm{mmHg}$, with a mean of $29.56 \pm 3.4 \mathrm{mmHg}$. On assessing the postoperative IOP over several points of time, the mean IOP had significantly dropped to $12.64 \pm 2.5$ $\mathrm{mmHg}$ at 1 month postoperatively, $14.12 \pm 3.2 \mathrm{mmHg}$ at 3 months postoperatively, $16.8 \pm 5.5 \mathrm{mmHg}$ at 6 months postoperatively, $14.44 \pm 2.3 \mathrm{mmHg}$ at 9 months postoperatively, and $14.3 \pm 1.6 \mathrm{mmHg}$ at 12 months; it plateaued at the same value for the next 9 months, then non-significantly increased to $14.32 \pm 1.7 \mathrm{mmHg}$ at 18 and 21 months postoperatively and $18.3 \pm 1.7 \mathrm{mmHg}$ after 24 months, with a statistically significant decrease over time.

Comparing each postoperative reading with the previous one, there were statistically significant changes at $1,3,6$, and 9 months postoperatively. There was a nonsignificant decrease in IOP when comparing IOP values at 9 and 12 months and a non-significant increase in IOP when comparing values at 18 and 21 months (Table 2, Figure 1).
Table I Baseline Characteristics of the Studied Patients

\begin{tabular}{|l|l|}
\hline & $\mathbf{N}=\mathbf{5 0}(\%)$ \\
\hline $\begin{array}{l}\text { Age at onset (months) } \\
\text { Rean } \pm \text { SD }\end{array}$ & $18.86 \pm 9.94$ \\
\hline Sex: & $6-40$ \\
Male & \\
Female & $26(52 \%)$ \\
\hline Consanguinity & $24(48 \%)$ \\
\hline $\begin{array}{l}\text { Negative } \\
\text { Positive }\end{array}$ & \\
\hline Horizontal corneal diameter (mm) & $31(62 \%)$ \\
Mean $\pm S D$ & $19(38 \%)$ \\
Range & \\
\hline Axial length (mm) & $14.56 \pm 0.812$ \\
Mean $\pm S D$ & $14-16$ \\
\hline Range & \\
\hline $\begin{array}{l}\text { CD ratio } \\
\text { Mean } \pm S D \\
\text { Range }\end{array}$ & $20.98 \pm 0.795$ \\
\hline
\end{tabular}

Comparing the number of medications used to control IOP among the studied patients, patients used three types of drug preoperatively (median 3 ), which significantly decreased to a range from zero to three drugs, with median 0 (Table 3 ).

A statistically significant positive correlation was detected between preoperative IOP and horizontal corneal diameter, axial length, and $\mathrm{CD}$ ratio, while a significant negative correlation was detected between preoperative IOP and age at onset (Table 4).

A positive correlation with high significance was detected between postoperative IOP and horizontal corneal diameter, axial length, and $\mathrm{CD}$ ratio, while there was a significant negative correlation between postoperative IOP and age at onset (Table 4).

A strong positive correlation was noticed between consanguinity and IOP values preoperatively and postoperatively (higher in those with positive consanguinity). There was a non-significant relation between patient's sex and IOP values, both preoperatively and postoperatively (Table 4).

A successful outcome was seen in 47 patients. Complete success was attained in 35 patients while qualified success occurred in 12 patients (Table 5, Figure 2).

Fifty-four percent reported no postoperative complications, while hyphema was the evident complication in $46 \%$ of cases (Table 6, Figure 3). 
Table 2 Preoperative and Postoperative Intraocular Pressure (IOP) Among the Studied Patients

\begin{tabular}{|c|c|c|c|c|}
\hline \multirow[t]{2}{*}{ Time Point } & \multicolumn{2}{|c|}{ IOP (mmHg) } & \multicolumn{2}{|l|}{ Test } \\
\hline & Mean \pm SD & Range & $t$ & $p$ \\
\hline Preoperative & $29.56 \pm 3.357$ & $21-36$ & & \\
\hline I month postop & $12.64 \pm 2.505$ & $10-19$ & 44.533 & $<0.001 * *$ \\
\hline 3 months postop & $14.12 \pm 3.173$ & ||$-2 \mid$ & -6.847 & $<0.00 I^{* *}$ \\
\hline 6 months postop & $16.8 \pm 5.525$ & $12-29$ & -6.762 & $<0.001^{* *}$ \\
\hline 9 month postop & $14.44 \pm 2.323$ & $12-26$ & 3.934 & $<0.00 I^{* *}$ \\
\hline 12 months postop & $14.3 \pm 1.619$ & $12-19$ & 0.686 & 0.496 \\
\hline I5 months postop & $14.3 \pm 1.619$ & $12-19$ & & \\
\hline 18 months postop & $14.3 \pm 1.619$ & $12-19$ & & \\
\hline 21 months postop & $14.32 \pm 1.659$ & $12-19$ & -1 & 0.322 \\
\hline 24 months postop & $14.32 \pm 1.659$ & $12-19$ & & \\
\hline$p(F)$ & \multicolumn{2}{|l|}{$<0.00 I^{* *}$} & & \\
\hline
\end{tabular}

Notes: $t$, Paired sample $t$-test; F, repeated measures ANOVA test; $* * 0.001$ is statistically highly significant.

Only three patients with failed surgery underwent further successful surgical intervention to control IOP, in the form of Ahmed valve implantation (Table 7).

There were statistically significant relations between surgical outcome and all of the variables consanguinity, age, axial length, horizontal corneal diameter, preoperative IOP, and $\mathrm{CD}$ ratio. All patients with qualified success reported positive consanguinity. Horizontal corneal diameter, preoperative IOP, CD ratio, and axial length were significantly higher in those with failed intervention. Age was significantly higher among those showing intervention success. On the other hand, there were non-significant relations between outcome and sex, occurrence of postoperative complications, and number of preoperative medications (Table 8).
There were statistically significant relations between type of success and all of the variables consanguinity, age, axial length, horizontal corneal diameter, preoperative IOP, and $\mathrm{CD}$ ratio. All patients with qualified success reported positive consanguinity. Horizontal corneal diameter, preoperative IOP, CD ratio, and axial length were significantly higher in those with qualified success. Age was significantly higher among those with complete success. On the other hand, there were non-significant relations between type of success and sex, occurrence of postoperative complications, and number of preoperative medications (Table 9).

\section{Discussion}

PCG remains a challenging problem for ophthalmic surgeons. Multiple suggestions have been proposed, including angle incisional surgery, goniotomy, and trabeculotomy as the first line of treatment for PCG, which depend on tearing the abnormal trabecular meshwork and inner wall of Shlemm's canal, in order to increase aqueous outflow, thus aiming to reduce the IOP. The choice of surgery depends on the clarity of the cornea. While goniotomy requires a clear cornea, trabeculotomy may be the best choice for patients with a cloudy or opaque cornea. ${ }^{14,20,21}$

Quigelly et al found that PCG patients with a corneal diameter less than $13 \mathrm{~mm}$ are the best candidates for an accurate localization of Shlemm's canal and probe entry, which give it a higher success rate. ${ }^{23}$ However, in PCG patients with a corneal diameter larger than $14 \mathrm{~mm}$, all of the limbal tissues are highly stretched, making the proper localization and entry into Schlemm's canal difficult, which can passively affect the trabeculotomy success

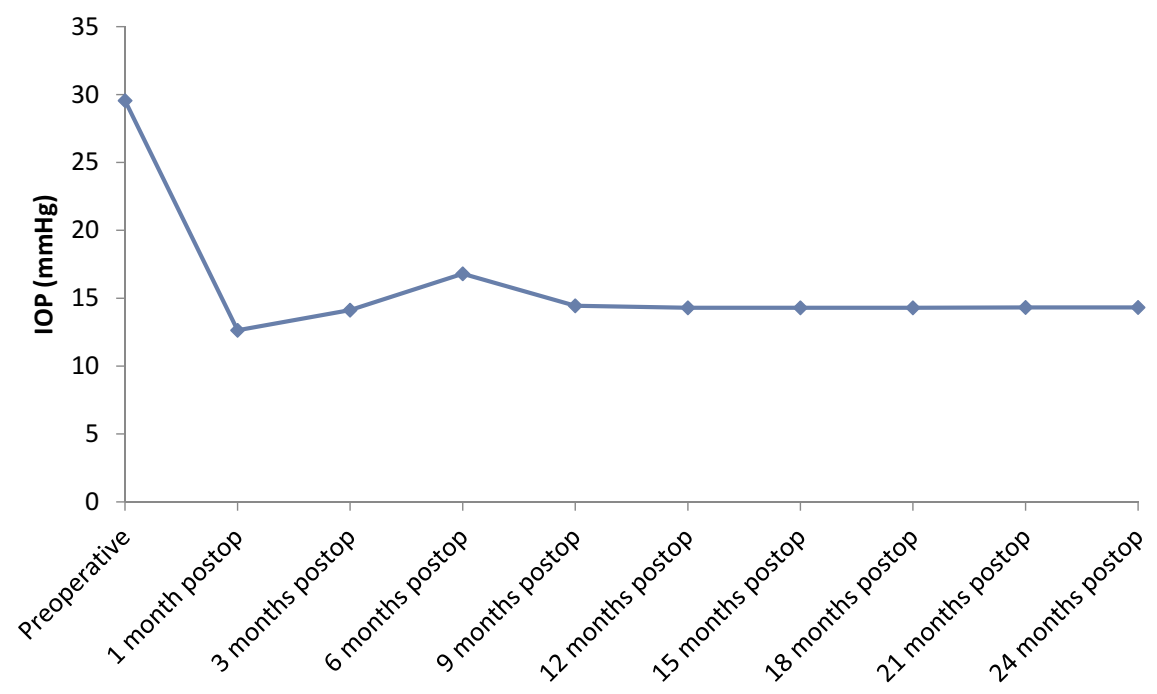

Figure I Line graph showing mean IOP among the studied patients preoperatively and postoperatively. 
Table 3 Comparison Between Preoperative and Postoperative Number of Medications

\begin{tabular}{|l|l|l|l|l|}
\hline \multirow{4}{*}{ Medications } & \multicolumn{2}{|l|}{ Time point } & Postoperative & \multicolumn{2}{l|}{ Test } \\
\cline { 2 - 5 } & Preoperative & $\mathbf{N}=\mathbf{5 0}(\%)$ & Wx & \multirow{2}{*}{} \\
\cline { 2 - 5 } & $\mathbf{N}=\mathbf{5 0}(\%)$ & 0 & -6.243 & $<0.001 * *$ \\
\hline $\begin{array}{l}\text { Median } \\
\text { Range }\end{array}$ & 3 & $0-3$ & & \\
\hline
\end{tabular}

Notes: ${ }^{* *} p \leq 0.001$ is statistically highly significant; $W x$, Wilcoxon signed rank test.

rate. ${ }^{23}$ Furthermore, Quigelly et al found that the high success rate of trabeculotomy, which was $100 \%$ in eyes with a diameter smaller than $14 \mathrm{~mm}$, was decreased to $67 \%$ in eyes with a corneal diameter greater than $14 \mathrm{~mm}$. Zhang et al found that PCG patients with a larger corneal diameter usually have a longer axial length; nevertheless, corneal diameter may be a reliable parameter for the assessment of severity and prognosis of PCG. Consequently, these authors highly recommended further modification of incisional angle surgery to improve the results in these cases. ${ }^{16}$

Fang et al and Rodrigues et al recommended adding constitutional surgical maneuvers, such as trabeculectomy, to trabeculotomy, or trabeculectomy with antimetabolites. However, these maneuvers may be accompanied by major or minor complications. Moreover, more restriction of success rates by rapid healing may occur. This problem could be solved

Table 4 Correlation/Relation Between Preoperative IOP and the Studied Parameters

\begin{tabular}{|c|c|c|c|c|}
\hline \multirow[t]{2}{*}{ Parameters } & \multicolumn{2}{|c|}{ Preoperative IOP } & \multicolumn{2}{|c|}{ Postoperative IOP } \\
\hline & $\boldsymbol{r}$ & $p$ & $\boldsymbol{r}$ & $p$ \\
\hline $\begin{array}{l}\text { Corneal } \\
\text { diameter }\end{array}$ & 0.751 & $<0.00 I^{* *}$ & 0.622 & $<0.001 * *$ \\
\hline CD ratio & 0.355 & $0.011 *$ & 0.371 & $0.008^{*}$ \\
\hline Axial length & 0.715 & $<0.001 * *$ & 0.701 & $<0.001 * *$ \\
\hline \multirow{2}{*}{$\begin{array}{l}\text { Age at } \\
\text { presentation }\end{array}$} & -0.548 & $<0.00 I^{* *}$ & -0.425 & $0.002 *$ \\
\hline & Mean \pm SD & Test & Mean \pm SD & Test \\
\hline \multicolumn{5}{|l|}{ Consanguinity } \\
\hline Negative & $27.7 I \pm 2.4$ & $t=-7.031$ & $13.45 \pm 0.81$ & $t=-5.415$ \\
\hline Positive & $32.58 \pm 2.36$ & $p<0.00 I^{* *}$ & $15.74 \pm 1.73$ & $p<0.00 I^{* *}$ \\
\hline \multicolumn{5}{|l|}{ Sex: } \\
\hline Male & $28.96 \pm 3.89$ & $t=-1.332$ & $14.35 \pm 1.94$ & $t=0.115$ \\
\hline Female & $30.21 \pm 2.59$ & $p=0.192$ & $14.29 \pm 1.33$ & $p=0.909$ \\
\hline
\end{tabular}

Notes: $r$, Pearson's correlation coefficient; $t$, independent sample $t$-test; $* p<0.05$ is statistically significant; ${ }^{* *} p \leq 0.001$ is statistically highly significant. by adding antifibrotics to the improve results. However, this could add the risk of bleb-related complications. ${ }^{25,26}$

Girkin et al found that an illuminated catheter-assisted 360-degree trabeculotomy enables the entire angle to be opened in a single session instead of opening approximately one-third of the angle, which turned out to be a successful approach. Some authors prefer carrying out circumferential trabeculotomy with filament-assisted goniotomy, even in PCG with a clear cornea, owing to the greater success of this method compared with goniotomy. ${ }^{29}$ However, this may need a longer learning curve and carries a risk of false passage, in addition to the drawback of attacking the whole circumference of the angle. Using a microcatheter with illumination may improve the results as this would help to attain more accurate localization and continuous visualization, as well as rapid detection of misdirection. Nevertheless, it may add additional cost and there is a lack of availability, especially in developing countries. ${ }^{28}$ Girkin et al reported a $91.65 \%$ qualified success rate using circumferential trabeculotomy with the aid of an illuminated microcatheter versus $53.8 \%$ success using conventional goniotomy. ${ }^{29}$

The current study preserved the use of traditional incisional surgery, which has a high success rate according to many authors, trials, and studies, with a modification that may improve efficacy and decrease the need for repeated surgery. Ab interno goniotomy combined with ab externo trabeculotomy may be an option to increase the success

Table 5 Distribution of the Studied Patients According to Success Rate

\begin{tabular}{|c|c|}
\hline Outcome & $\mathbf{N}=50(\%)$ \\
\hline Success & 47 (94\%) \\
\hline Failure (need further surgical intervention) & $3(6 \%)$ \\
\hline \multicolumn{2}{|l|}{ Type of success } \\
\hline Complete & $35(70 \%)$ \\
\hline Qualified & 12 (24\%) \\
\hline
\end{tabular}




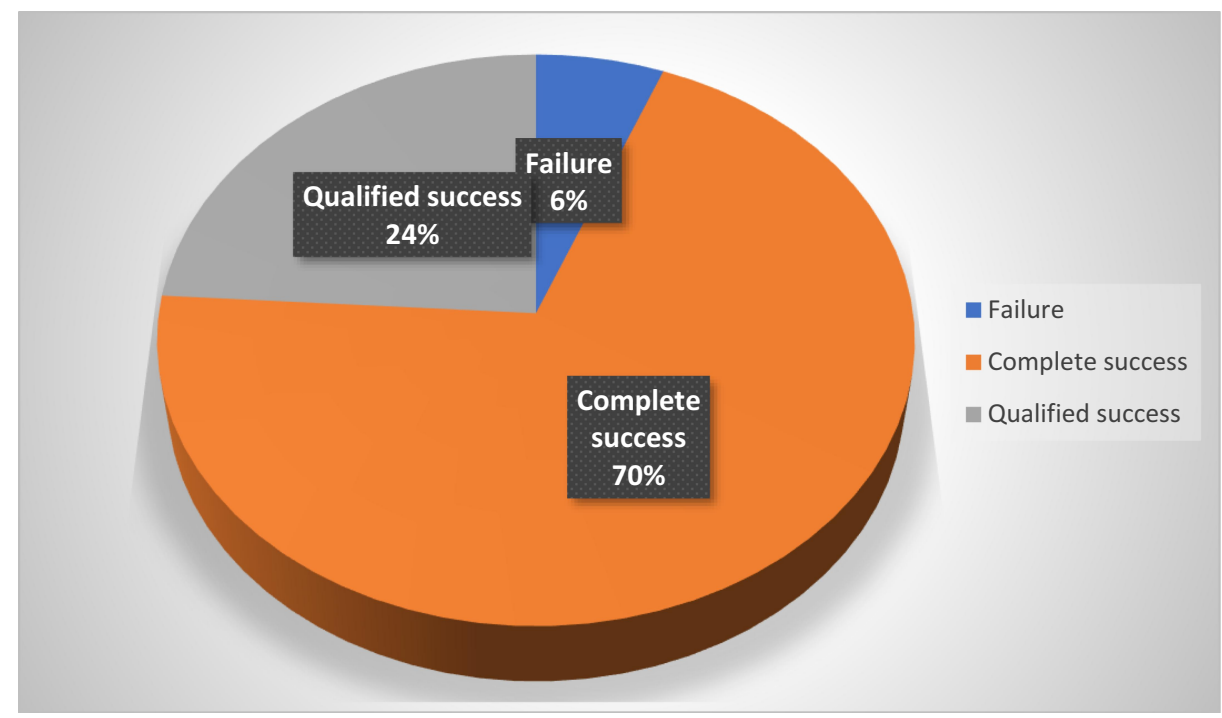

Figure 2 Pie chart showing distribution of the studied patients according to success.

rate of surgery in PCG patients with a corneal diameter greater than $14 \mathrm{~mm}$.

The results reveal that this technique has a success rate of $94 \%$ of cases, with complete success rate of $70 \%$, qualified success of $24 \%$, and failure of $6 \%$.

Other studies on goniotomy revealed that the goniotomy success rate varied between $50 \%$ and $90 \%$ based on the number of goniotomy surgeries, the severity of the disease, and the diameter and clarity of the cornea. ${ }^{30}$ Nevertheless, the current results using a combined goniotomy-trabeculotomy technique indicate higher success rates as it approaches a wider area of angle. Huang et al found that the success rate using trabeculotomy was $90.5 \%, 85.7 \%, 85.7 \%$, and $85.7 \%$ at $1,3,4$, and 5 -year follow-up, respectively. ${ }^{15}$ Moreover, this success rate was decreased to $69 \%$ in patients who underwent multiple surgeries. Concurring with this, Ou et al found a success rate between $87 \%$ and $92 \% .{ }^{31}$ However, the success rate in the current study was higher than these previous results. The author attributes this high success rate to the increased area of treatment of Shlemm's canal achieved through combining goniotomy with trabeculotomy.

Table 6 Distribution of the Studied Patients According to Development of Complications

\begin{tabular}{|l|l|}
\hline Complications & $\mathbf{N}=\mathbf{5 0}$ \\
\hline None & $27(54 \%)$ \\
Hyphema & $23(46 \%)$ \\
\hline
\end{tabular}

In agreement with the present findings, Neustein and Beck compared the long-term surgical success rate of circumferential trabeculotomy to conventional angle surgery. ${ }^{32}$ They concluded that circumferential trabeculotomy provides more successful long-term results than conventional surgery over 2 years. A success rate of $81 \%$ resulted from circumferential trabeculotomy in 58 eyes, and $31 \%$ from conventional surgery in 42 eyes. The success rate in the present study also coincides with a study by Mendicino et al that concluded a success rate of $92 \%$ of cases treated with 360 trabeculotomy in comparison with $57.5 \%$ with goniotomy. ${ }^{27}$

The results of this study indicate that the IOP had decreased from $29.6 \pm 3.6$ to $14.32 \pm 1.7$ at the end of followup period, which was 24 months. This coincides with Neustein and Beck, who concluded that the postoperative IOP was lower in circumferential than in conventional
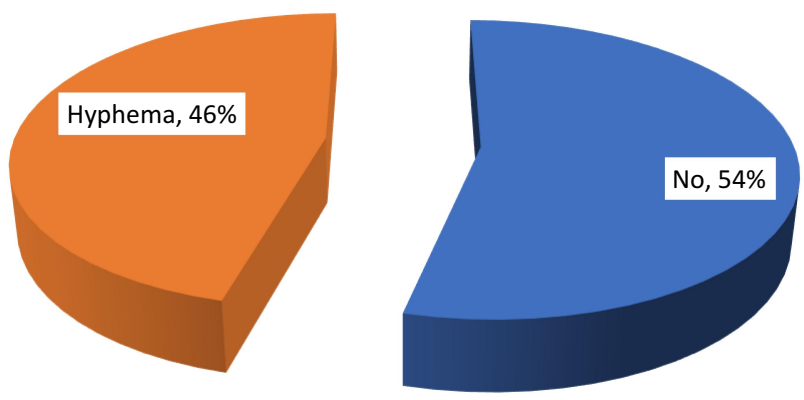

Figure 3 Pie chart showing distribution of the studied patients according to postoperative complications. 
Table 7 Distribution of Patients According to Next Surgical Intervention

\begin{tabular}{|l|l|}
\hline Next Surgical Intervention & $\mathbf{N}=\mathbf{5 0}$ \\
\hline None & $47(94 \%)$ \\
Valve implantation & $3(6 \%)$ \\
\hline
\end{tabular}

trabeculotomy, $15 \pm 3.6$ versus $18.2 \pm 7.0 .^{32}$ Another study, by El Sayed and Gawdat, claimed comparable results of circumferential trabeculotomy with an illuminated microcatheter and two-site rigid probe trabeculotomy. ${ }^{33}$

The current study detected a significant correlation between corneal diameter and success rate. The success rate was higher in cases with a corneal diameter less than $14.5 \mathrm{~mm}$ than in cases with a corneal diameter more than $14.5 \mathrm{~mm}$. In accordance with our findings, Al Hazmi et al classified the severity of buphthalmos into mild when the corneal diameter is less than $13 \mathrm{~mm}$ and moderate when

Table 8 Relation Between Surgical Outcome and the Studied Parameters

\begin{tabular}{|c|c|c|c|c|}
\hline \multirow[t]{3}{*}{ Parameters } & \multicolumn{2}{|l|}{ Outcome } & \multicolumn{2}{|l|}{ Test } \\
\hline & \multirow{2}{*}{$\begin{array}{l}\text { Failure } \\
\mathrm{N}=3 \text { (\%) }\end{array}$} & \multirow{2}{*}{$\begin{array}{l}\text { Success } \\
\mathrm{N}=47 \text { (\%) }\end{array}$} & \multirow[t]{2}{*}{$X^{2} / t$} & \multirow[t]{2}{*}{$p$} \\
\hline & & & & \\
\hline \multicolumn{5}{|l|}{ Gender } \\
\hline Male & $2(66.7)$ & $24(51.1)$ & Fisher & $>0.999$ \\
\hline Female & I (33.3) & $23(48.9)$ & & \\
\hline \multicolumn{5}{|l|}{ Consanguinity } \\
\hline Negative & $0(0)$ & $31(66)$ & Fisher & $0.049 *$ \\
\hline Positive & $3(100)$ & $16(34)$ & & \\
\hline \multicolumn{5}{|l|}{ Complications } \\
\hline None & $0(0)$ & $27(57.4)$ & Fisher & 0.09 \\
\hline Hyphema & $3(100)$ & $20(42.6)$ & & \\
\hline \multicolumn{5}{|l|}{ Age } \\
\hline Mean $\pm S D$ & $10.0 \pm 3.464$ & $19.43 \pm 9.967$ & -3.182 & $0.014 *$ \\
\hline \multicolumn{5}{|l|}{ Axial length } \\
\hline Mean $\pm S D$ & $22.0 \pm 0$ & $20.91 \pm 0.775$ & 9.594 & $<0.001^{* *}$ \\
\hline \multicolumn{5}{|l|}{$\begin{array}{l}\text { Horizontal corneal } \\
\text { diameter }\end{array}$} \\
\hline Mean $\pm S D$ & $16.0 \pm 0$ & $14.47 \pm 0.747$ & 14.05 & $<0.001^{* *}$ \\
\hline \multicolumn{5}{|l|}{ Preoperative IOP } \\
\hline Mean $\pm S D$ & $34.67 \pm 1.155$ & $29.23 \pm 3.184$ & 2.918 & $0.005^{*}$ \\
\hline \multicolumn{5}{|l|}{ CD ratio } \\
\hline Mean $\pm S D$ & $1.0 \pm 0$ & $0.79 \pm 0.414$ & 3.526 & $0.001 * *$ \\
\hline \multicolumn{5}{|l|}{$\begin{array}{l}\text { Preoperative } \\
\text { medications }\end{array}$} \\
\hline Median (range) & $3(3-16)$ & $3(3-16)$ & $Z(-0.983)$ & 0.326 \\
\hline
\end{tabular}

Notes: $t$, Independent sample $t$-test; $Z$; Mann-Whitney test; ${ }^{*} p<0.05$ is statistically significant; ** $p \leq 0.001$ is statistically highly significant.
Table 9 Relation Between Type of Success and the Studied Parameters

\begin{tabular}{|c|c|c|c|c|}
\hline \multirow[t]{3}{*}{ Parameters } & \multicolumn{2}{|l|}{ Success } & \multicolumn{2}{|l|}{ Test } \\
\hline & Complete & Qualified & $X^{2} / t$ & $p$ \\
\hline & $\mathrm{N}=35$ (\%) & $\mathrm{N}=12$ (\%) & & \\
\hline $\begin{array}{l}\text { Gender } \\
\text { Male } \\
\text { Female }\end{array}$ & $\begin{array}{l}19(54.3) \\
16(45.7)\end{array}$ & $\begin{array}{l}5(41.7) \\
7(58.3)\end{array}$ & 0.569 & 0.450 \\
\hline $\begin{array}{l}\text { Consanguinity } \\
\text { Negative } \\
\text { Positive }\end{array}$ & $\begin{array}{l}31(88.6) \\
4(11.4)\end{array}$ & $\begin{array}{l}0(0) \\
12(100)\end{array}$ & Fisher & $<0.001 * *$ \\
\hline $\begin{array}{l}\text { Complications } \\
\text { None } \\
\text { Hyphema }\end{array}$ & $\begin{array}{l}13(37.1) \\
22(62.9)\end{array}$ & $\begin{array}{l}7(58.3) \\
5(41.7)\end{array}$ & 1.641 & 0.2 \\
\hline $\begin{array}{l}\text { Age } \\
\text { Mean } \pm S D\end{array}$ & $22.46 \pm 9.778$ & $10.58 \pm 2.314$ & 6.661 & $<0.001 * *$ \\
\hline $\begin{array}{l}\text { Axial length } \\
\text { Mean } \pm S D\end{array}$ & $20.6 \pm 0.604$ & $21.83 \pm 0.389$ & -8.124 & $<0.001 * *$ \\
\hline $\begin{array}{l}\text { Horizontal corneal } \\
\text { diameter } \\
\text { Mean } \pm S D\end{array}$ & $14.14 \pm 0.494$ & $15.42 \pm 0.515$ & -7.632 & $<0.001^{* *}$ \\
\hline $\begin{array}{l}\text { Preoperative IOP } \\
\text { Mean } \pm S D\end{array}$ & $28.06 \pm 2.589$ & $32.67 \pm 2.103$ & -5.558 & $<0.001 * *$ \\
\hline $\begin{array}{l}\text { CD ratio } \\
\text { Mean } \pm S D\end{array}$ & $0.7 \mid \pm 0.458$ & $1 \pm 0$ & -3.668 & $0.00 I^{* *}$ \\
\hline $\begin{array}{l}\text { Preoperative } \\
\text { medications } \\
\text { Median (range) }\end{array}$ & $3(3-14)$ & $3(3-16)$ & $Z(-1.211)$ & 0.226 \\
\hline
\end{tabular}

Notes: $t$, Independent sample $t$-test; $Z$, Mann-Whitney test; ${ }^{*} p \leq 0.001$ is statistically highly significant.

the corneal diameter lies between 13 and $14.5 \mathrm{~mm}$, while the severe type was documented when the corneal diameter was more than $14.5 \mathrm{~mm}$. They found that the success rate of either goniotomy or trabeculotomy in mild cases was higher than that in moderate and severe cases, regardless of the technique used in the surgical approach. ${ }^{19}$ Filous and Brunova clarified the cause of this as being changes in the curvature of Shlemm's canal in these cases, which may be not compatible with the curvature of the rigid probe, and they recommended different probes for different diameters of 10,12 , and $14 \mathrm{~mm}$. They found an $87 \%$ success rate with trabeculotomy surgery. ${ }^{34}$

In addition, our results showed a significant correlation between success rate and preoperative IOP. This is consistent with Al Hazmi et al, who classified the severity of buphthalmos based on preoperative IOP into mild when the IOP is less than $25 \mathrm{mmHg}$, moderate when the IOP lies 
between 25 and $35 \mathrm{mmHg}$, and severe when the IOP is greater than $35 \mathrm{mmHg}$. They found that the success rates of both goniotomy and trabeculotomy were higher in mild than in moderate and severe cases. Their results were not linked to a certain surgical technique. They also recommended combined trabeculotomy-trabeculectomy as a modified technique in moderate and severe cases. ${ }^{19}$

Furthermore, the present results revealed a significant positive correlation between success rate and age of onset; older age was associated with a less severe form of the disease and higher success rates. These findings coincide with those of Gramer et al, who concluded that early onset of PCG is usually accompanied by a more aggressive form of the disease. They found that the main predictor of success is the timing of diagnosis, and that the success rate was higher among patients diagnosed between the ages of 1 month and 2 years. ${ }^{35}$

Consanguinity in the current study was detected in $38 \%$ of cases. A negative correlation between consanguinity and success rate has been detected. This can be explained by the presence of higher corneal diameter, $\mathrm{CD}$ ratio, and preoperative IOP in patients with positive consanguinity. In accordance with our findings, Martin et al discovered a correlation between consanguinity and poor surgical and medical outcomes of treatment of PCG. ${ }^{36}$

Hyphema in the current study was detected in $47 \%$ of cases, and all of them responded to medical treatment and resolved spontaneously a few days later, without the need for any further surgical intervention. In accordance with our results, Sharawy and Bhartiya found that hyphema is the most common drawback of goniotomy. ${ }^{37}$

Unlike other studies, no major complications in goniotomy, such as irido-dialysis, peripheral anterior synechia, cyclodialysis, or lenticular injury, occurred in this study. ${ }^{6}$ Similarly, we did not see any major complications in trabeculotomy, such as false passage or choroid hemorrhage. The only complication encountered in this study was hyphema, which appeared commonly in trabeculotomy, which coincides with previous studies. ${ }^{15,16,38}$

All failed cases underwent Ahmed valve implantation surgery and finally achieved controlled IOP. This decision was based on the concept that valve implantation depends on aqueous withdrawal into the posterior bleb, away from any scarred conjunctiva, that may negatively affect the results.

In conclusion, combined ab interno goniotomy with $a b$ externo trabeculotomy may be a highly recommended surgical choice for PCG cases with a corneal diameter larger than $14 \mathrm{~mm}$.

This study could be considered the first to combine ab interno goniotomy with ab externo trabeculotomy to manage advanced PCG.

Limitations of this study are the small number of cases and the absence of a control group. These may be justified by the availability of multiple studies that revealed the success rate of each single technique alone.

\section{Acknowledgment}

The author thanks the Research Institute of Ophthalmology (RIO) for support during the conducting of this study.

\section{Disclosure}

The author declares no conflicts of interest for this work.

\section{References}

1. Fan BJ, Wiggs JL. Glaucoma: genes, phenotypes, and new directions for therapy. J Clin Invest. 2010;120(9):3064-3072. doi:10.1172/JCI43085

2. Sarfarazi M, Stoilov I, Schenkman JB. Genetics and biochemistry of primary congenital glaucoma. Ophthalmol Clin North Am. 2003;16 (4):543-554. doi:10.1016/S0896-1549(03)00062-2

3. Al-Rajhi A, Awad A, Badeed O, et al. Causes of blindness in students attending school for the blind in Saudi Arabia. Saudi J Ophthalmol. 2003;17:276-280.

4. Liu B, Huang W, He M, et al. An investigation on the causes of blindness and low vision of students in blind school in Guangzhou. Yan Ke Xue Bao. 2007;23(2):117-120.

5. Aziz A, Fakhoury O, Matoni F, et al. Epidemiology and clinical characteristics of primary congenital glaucoma. J Fr Ophthalmol. 2015;38(10):960-966. doi:10.1016/j.jfo.2015.04.018

6. Mandal AK, Chakrabarti D. Update on congenital glaucoma. Indian J Ophthalmol. 2011;59(1):148-157. doi:10.4103/0301-4738.73683

7. lewis CJ, Hedberg-Buenz A, Deluca AP, et al. Primary congenital and developmental glaucomas. Hum Mol Genet. 2017;26(R1):R28-R36. doi:10.1093/hmg/ddx205

8. Francois J. Congenital glaucoma and its inheritance. Ophthalmologica. 1980;181(2):61-73. doi:10.1159/000309028

9. Badawi AH, AL-Muhaylib AA, AL Owaifeer AA, et al. Primary congenital glaucoma: an updated review. Saudi J Ophthalmol. 2019;33(4):382-388. doi:10.1016/j.sjopt.2019.10.002

10. Aponte EP, Diehl N, Mohney BG. Medical and surgical outcomes in childhood glaucoma: a population-based study. JAAPOS. 2011;15 (3):263-267.

11. Zagora SL, Funnell CL, Martin FJ, et al. Primary congenital glaucoma outcomes: lessons from 23 years of follow up. Am J Ophthalmol. 2015;159(4):788-796. doi:10.1016/j.ajo.2015.01.019

12. Fung DS, Roensch MA, Kooner SK, et al. Epidemiology and characteristics of childhood glaucoma: results from Dallas glaucoma registry. Clin Ophthalmol. 2013;7:1739-1746. doi:10.2147/OPTH.S45480

13. Alanazi FF, Song JC, Mousa A, et al. Primary and secondary congenital glaucoma; baseline features of a registry at King Khalid eye specialist hospital, Riyadh, Saudi Arabia. Am J Ophthalmol. 2013;155(5):882-889. doi:10.1016/j.ajo.2012.12.006 
14. Cai Y, Li MY, Shen YY, et al. Long term effect of trabeculotomy on primary congenital glaucoma. Zhonghua Yan Ke Za Zhi. 2004;40 (11):733-736.

15. Huang JL, Huang -J-J, Zhong Y-M, et al. Surgical outcomes of trabeculotomy in newborns with primary congenital glaucoma. Chin Med J. 2016;129:2178-2183. doi:10.4103/0366-6999.189925

16. Zhang X, Du S, Fan Q, et al. Long- term surgical outcomes of primary congenital glaucoma in china. Clinics (Sao Paulo). 2009;64:543-551. doi:10.1590/S1807-59322009000600009

17. Ikeda H, Ishigooka H, Muto T, et al. Long term outcome of trabeculotomy for the treatment of developmental glaucoma. Arch Ophthalmol. 2004;122(8):1122-1128. doi:10.1001/archopht.12 2.8.1122

18. Ben-Zion I, Tomkis O, Moore DB, et al. Surgical results in the management of advanced primary congenital glaucoma in a rural pediatric population. Ophthalmology. 2011;118(2):231-235. doi:10.1016/j.ophtha.2010.02.027

19. Al Hazmi A, Awad A, Zwan J, et al. Correlation between surgical success and severity of glaucoma. $\mathrm{Br} J$ Ophthalmol. 2005;89 (4):449-453. doi:10.1136/bjo.2004.047761

20. Chan YU, Choy BN, Ng AL, et al. Review on the management of primary congenital glaucoma. J Curr Glaucoma Practice. 2015;9 (3):92-99. doi:10.5005/jp-journals-10008-1192

21. Yalvac IS, Satana B, Suveren A, et al. Success of trabeculotomy in patients with congenital glaucoma operated on within 3 months of birth. Eye. 2007;21:459-464. doi:10.1038/sj.eye.6702223

22. Sampaolesi R, Zarate J, Sampaolesi JR. Results of surgery for congenital glaucoma. The Glaucomas: $V$ I Pediatric Glaucoma. 2009:187-191.

23. Quigelly HA. Childhood glaucoma: results with trabeculotomy and study of reversible cupping. Ophthalmology. 1982;89:210-226.

24. Cronemberger S, Calixto N, Avellar Milhomens TG, et al. Effect of intraocular pressure control on central corneal thickness, horizontal corneal diameter, and axial length in primary congenital glaucoma. JAAPOS. 2014;18:433-436.

25. Fang L, Guo X, Yang Y, et al. Trabeculotomy versus trabeculotomy trabeculectomy for primary congenital glaucoma: study protocol of a randomized controlled trial. BMJ Open. 2020;10920.

26. Rodrigues AM, Junior AP, Montezano FT, et al. Comparison between results of trabeculectomy in primary congenital glaucoma with and without use of mitomycin C. J Glaucoma. 2004;13(3):228-232. doi:10.1097/00061198-200406000-00010
27. Mendicino ME, Lynch MG, Drack A, et al. Long term surgical and visual outcomes in primary congenital glaucoma:360 degrees trabeculotomy versus goniotomy. JAAPOS. 2000;4(4):205-210.

28. Sarkisian SR. An illuminated micro catheter for 360 degree trabeculotomy in congenital glaucoma: a retrospective case series. JAAPOS. 2010;14(5):412-416.

29. Girkin CA, Rhodes L, McGwin G, et al. Goniotomy versus circumferential trabeculotomy with an illuminated microcatheter in congenital glaucoma. JAAPOS. 2012;16:424-427.

30. Chang TC, Cavuoto KM. Surgical management in primary congenital glaucoma: four debates. J Ophthalmol. 2013;5:612708.

31. Ou Y, Caprioli J. Surgical management of pediatric glaucoma. Dev Ophthalmol. 2012;50:157-172.

32. Neustein R, Beck A. Circumferential trabeculotomy versus conventional angle surgery; comparing long term surgical success and clinical outcomes in children with primary congenital glaucoma. Am J Ophthalmol. 2017;183:17-24. doi:10.1016/j.ajo.2017.08.008

33. El Sayed YM, Gawdat G. Microcatheter-assisted trabeculotomy versus 2-site trabeculotomy with the rigid probe trabeculotome in primary congenital glaucoma. J Glaucoma. 2018;27(4):371-376. doi:10.1097/IJG.0000000000000892

34. Filous A, Brunova B. Results of the modified trabeculotomy in the treatment of primary congenital glaucoma. JAAPOS. 2002;6 (3):182-186.

35. Gramer EM, Tausch M, Kraemer C. Time of diagnosis, reoperations and long term results of goniotomy in the treatment of primary congenital glaucoma; a clinical study. Int Ophthalmol. 1996;20(1-3):117-123. doi:10.1007/BF00212957

36. Martin SN, Sutherland J, Levin AV, et al. Molecular characterization of congenital glaucoma in consanguineous Canadian community; a step towards preventing glaucoma related blindness. J Med Genet. 2000;37(6):422-427. doi:10.1136/jmg.37.6.422

37. Sharawy T, Bhartiya S. Surgical management of glaucoma; evolving paradigms. Indian J Ophthalmol. 2011;59:123-130. doi:10.4103/ 0301-4738.73692

38. Khalil DH, Abdelhakim MSAE. Primary trabeculotomy compared to combined trabeculotomy trabeculectomy in congenital glaucoma:3-years study. Acta Ophthalmol. 2016;94(7):e550-4. doi:10.1111/aos. 13018
Clinical Ophthalmology

\section{Publish your work in this journal}

Clinical Ophthalmology is an international, peer-reviewed journal covering all subspecialties within ophthalmology. Key topics include: Optometry; Visual science; Pharmacology and drug therapy in eye diseases; Basic Sciences; Primary and Secondary eye care; Patient Safety and Quality of Care Improvements. This journal is indexed on PubMed

\section{Dovepress}

Central and CAS, and is the official journal of The Society of Clinical Ophthalmology (SCO). The manuscript management system is completely online and includes a very quick and fair peer-review system, which is all easy to use. Visit http://www.dovepress.com/ testimonials.php to read real quotes from published authors. 